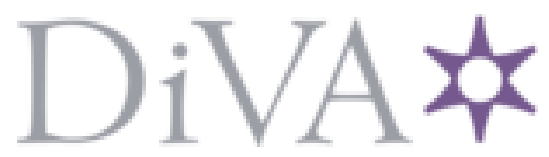

http://www.diva-portal.org

This is the published version of a paper published in Umweltwissenschaften und Schadstoff-Forschung.

Citation for the original published paper (version of record):

Suares Rocha, P., Keiter, S., Pompeo, M., Mariani, C., Brandimarte, A. et al. (2006)

Weight-of-Evidence-Studie zur Sedimentbelastung des Tietê River in Brasilien.

Umweltwissenschaften und Schadstoff-Forschung, 18(1): 70

Access to the published version may require subscription.

N.B. When citing this work, cite the original published paper.

Permanent link to this version:

http://urn.kb.se/resolve?urn=urn:nbn:se:oru:diva-39640 


\title{
Projektvorstellung
}

\section{Weight-of-Evidence-Studie zur Sedimentbelastung des Tietê River in Brasilien}

\author{
Paula Suares Rocha ${ }^{1 *}$, Steffen Keiter ${ }^{1}$, Marcelo Luiz Martins Pompêo ${ }^{2}$, Carolina Fioriollo Mariani², \\ Ana Lúcia Brandimarte ${ }^{2}$, Thomas-Benjamin Seiler ${ }^{1}$, Thomas Kosmehl1, Melanie Böttcher ${ }^{1}$, Jan Wölz, ${ }^{1}$, \\ Thomas Braunbeck ${ }^{1}$, Volker Storch ${ }^{1}$ und Henner Hollert ${ }^{1}$ \\ ${ }^{1}$ Institut für Zoologie, Aquatische Ökologie and Toxikologie, Abteilung Morphologie und Ökologie, Universität Heidelberg, \\ Im Neuenheimer Feld 230, D-69120 Heidelberg \\ ${ }^{2}$ Abteilung für Ökologie, Institut für Biowissenschaften, Universität São Paulo, Rua do Matão, Travessa 14, 321 - Butantã, \\ 05508-900 - São Paulo, SP - Brazil
}

\footnotetext{
* Korrespondenzautor (rocha@zoo.uni-heidelberg.de)
}

Der Fluss Tietê im südlichen Brasilien hat eine Gesamtlänge von $1150 \mathrm{~km}$ und durchquert den gesamten Bundesstaat Sao Paulo. Der Höhenunterschied zwischen Quelle und Mündung beträgt etwa $860 \mathrm{~m}$ und wird mittels einer Reihe von Stauhaltungen zur Stromerzeugung genutzt. Sowohl hinsichtlich seiner organischen als auch der anorganischen Schadstofffrachten gilt der Tietê als stark belastet. Bereits fünf Kilometer nach der Quelle beginnt die Verunreinigung des Tietê und erreicht ihren Höhenpunkt in São Paulo. Dort gleicht der Tietê einem vollständig verschmutzten und stinkenden Abwasserkanal, in dem selbst Autos und Möbelstücke umher treiben. Nach weiteren $300 \mathrm{~km}$, nahe der Kleinstadt Barra Bonita, ist die Wasserqualität bereits deutlich verbessert.

Die Bewertung von Sedimenten nimmt in diesem Weight-ofevidence-Projekt einen hohen Stellenwert ein, da aus verschiedenen anderen Studien bekannt ist, dass viele Schadstoffeinträge eine hohe Affinität zu Schwebstoffen besitzen, an diesen adsorbieren und dadurch der Wassersäule entzogen werden. Die Sedimente stellen nach Sedimentation der Schwebstoffe eine Senke für diese Schadstoffe dar; sie können in stauregulierten Flusssystemen insbesondere durch Hochwasserereignisse, Verklappungen und Spülungen von Stauhaltungen wieder remobilisiert werden. Sedimentgebundene Schadstoffe sind aus zahlreichen Studien für ihre nachteilige Wirkung insbesondere gegenüber benthischen Fischen bekannt und können bei Verzehr von kontaminierten Fischen ein Gesundheitsrisiko für den Menschen darstellen. Auch die Sedimentation kontaminierter Schwebstoffe auf landwirtschaftlich genutzten Überflutungsflächen und eine mögliche Beeinträchtigung des Trinkwassers können problematisch sein.

Ziel dieses Projektes ist es, eine umfassende Weight-of-evidenceStudie durchzuführen, bei der nicht nur die Sedimentqualität des Tietê sondern auch das Ausmaß der ökotoxikologischen Belastung in situ bewertet werden sollen, um eine Risikoabschätzung und ggf. eine Toxicity Reduction Evaluation zu ermöglichen.

Hierzu werden an sieben verschiedenen Standorten entlang des Tietê Sedimentproben für ökotoxikologische Wirktests und chemische Analysen entnommen sowie Fische für Mikrokerntests in situ gefangen (Abb. 1): Während die Quelle des Tietê und die Stauhaltung Ponte nova als Referenzstandorte oberhalb von São Paulo dienen, repräsentiert die Stauhaltung Billings einen Flussabschnitt, der von der Metropole ökotoxikologisch stark beeinträchtigt wird. Für die stromabwärts gelegenen Stau-

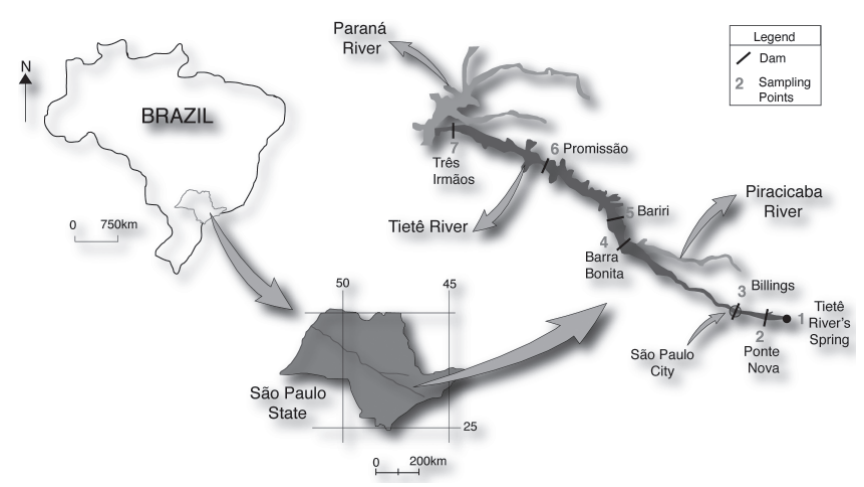

Abb. 1: Standorte der Sedimentprobennahmen entlang des Tietê

haltungen Bairi und Bara Bonita ist aus chemischen Untersuchungen bereits eine Abnahme der partikelgebunden Schadstoffkonzentrationen bekannt. Promissao und Três Irmaos gelten aus vorhergehenden Untersuchungen als relativ gering belastet.

Für eine umfassende ökotoxikologische Risikobewertung des Tietê werden in diesem Projekt sowohl akut toxische als auch spezifische Endpunkte (mutagene, gentoxische, teratogene, östrogene und dioxinähnliche Wirksamkeit) eingesetzt. Die akute Cytotoxizität wird im Neutralrottest mit der Zelllinie RTL-W1 aus der Regenbogenforelle (Oncorhynchus mykiss) ermittelt. Unter Verwendung des Sedimentkontakttests mit Danio rerio und des Bakterienkontakttests mit Arthrobacter globiformis werden native Sedimentproben hinsichtlich ihrer bioverfügbaren Toxizität untersucht. Die mutagene, gentoxische und dioxinähnliche Wirksamkeit von Sedimentextrakten wird mit dem Ames-Test, dem Comet- und EROD-Assay mit der Zelllinie RTL-W1 ermittelt. Der Mikronukleustest mit Fischzellen stellt eine geeignete Methode dar, um sowohl gentoxische In vivo- als auch In situUntersuchungen durchzuführen und die Gewässerqualität zu überprüfen. In verschiedenen Freiland- und Laboruntersuchungen konnte gezeigt werden, dass in Fischerythrocyten nach Exposition mit unterschiedlichen Schadstoffen die Anzahl der Mikronuklei deutlich zunimmt. Daher wird der Mikronukleustest mit Erythrocyten von Fischen aus dem Tietê in dieser Studie eingesetzt, um die Relevanz der gewonnen In vitro-Biotests für die aquatische Gemeinschaft in situ zu überprüfen. In dem Projekt sollen weiterhin die Konzentrationen von organischen und anorganischen Schadstoffen erfasst werden. 